\title{
LOS JUDIOS Y EL CABILDO CATEDRALICIO DE MURCIA EN EL SIGLO XV
}

Por

FRANCISCO REYES MARSILLA DE PASCUAL Universidad de Córdoba 


\section{INTRODUCCION.}

Los judíos de Castilla, después de los ataques de que habran sido objeto a finales del siglo XIV, conocen una época de relativo esplendor en la primera mitad del siglo XV. Es cierto que a comienzos de este siglo se promulgaron importantes disposiciones legales contra los hebreos: en 1405, y fundamentalmente en 1412, con el famoso uordenamiento sobre el encerramiento de los judíos e de los moros" (1), mientras la Iglesia, por su parte, promulgaba también una bula de $\mathrm{Be}$ nedicto XIII en contra de los judios (2) y el pueblo se alzaba masivamente contra las aljamas judáicas; pero la realidad es que ni estas medidas legales y eclesiásticas ni las violencias antisemitas de las masas pasaron de ser cosa algo meramente coyuntural.

En líneas generales podemos afirmar que desde el reinado de Juan II de Castilla hasta el comienzo del de los Reyes Católicos los judíos castellanos gozan de una gran protección por parte de las autoridades tanto civiles como eclesiásticas. A mediados del siglo XV encontramos de nuevo a los judios ocupando puestos importantes en la

(1) Mrre, E.: «Los judios y la Corona de Castilla en el tránsito al siglo XV». En C.H.E. Anexos a la Rev. Hispania 3 (Madrid, 1969), p. 361-363; AMADOR DE LOS RIOS, J.: aHistoria social, politica y religiosa de los judlos de España y Portugalp. Madrid, 1960 (Reimp. 1973). Apéndice documental XIX, p. 965-970.

(2) AIIADOR DI: l.os RIOS, J.: o. c., ap. doc. XX, p. 970-985. 
administración real, sobre todo como arrendadores de impuestos, al igual que acaparan los arrendamientos de las rentas eclesiásticas; todo lo cual dá un nuevo impulso a los sentimientos populares antisemitas, si bien ahora se concretan más contra los conversos que contra los judíos; muchos de estos conversos harán brillante carrera en cl seno de la Iglesia: recordemos al obispo murciano de esta época don Pablo de Santa María y a toda la familia burgalesa de los Cartagena (3).

En cuanto a Murcia parece ser que toda la problemática de mediados del siglo XV en relación con los judíos tiene escasa influencia (4). Desde el punto de vista proteccionista los judíos gozan de un prestigio, inusual en la Castilla de esta época, tanto de parte del concejo murciano como de parte de la Iglesia, y más concretamente del cabildo de la catedral y del obispo, pues como señala el Profesor Torres Fontes (5) la marginación geográfico-política del Reino de Murcia respecto a Andalucía y Castilla permitió que sus autoridades, conocedoras de lo que había acontecido en diversas ciudades andaluzas y castellanas, pudieran anticiparse a cualquier intento de acción violenta en contra de la población hebrea.

\section{LOS JUDIOS Y EL. CABILDO DE L.A IGLESIA DE CARTAGE- NA (1468-1478). (6).}

En contra de todo lo establecido por legislación eclesiástica y sinodal de la Iglesia de Cartagena repecto a las medidas discriminato-

(3) Si:krano, L.: aLos conversos don Pablo de Santa María y don Alonso de Cartagenav. C.S.I.C. Maclrid, 1942.

(4) TuRris Fontes, J.: alos judios murcianos a fines del siglo XIV y comienzos del siglo XV. En M.M.MH. 3 (Murcia, 1977), p. 57-107; Mol.N. M/M.NA, A. L.: al.os judios en el reinado de Pedro lo. En M.M.AIu. (Murcia, 1977), p. 9-40.

(5) O. c.

(6) Nuestra principal fuente documental para este estudio ha sido el códice B.2 del A.C.Mu. Se trata del único libro de protocolos existente en el citado Archivo, del notario Juan Sanchez de Santisteban, notario público de Murcia, y abarca desde el ano 1468,30 de septicmbre, al 1473, 13 de noviembre. También hemos utilizado los cólices 213,236 y 237, asl como el códice, $s / n$, con las constituciones sinodales de don Jerónimo Manrique de l.ara que, aunque del siglo XV'l, incluye importantes documentos y bulas pontificias bajomedievales. Igualmente el al ibro viejo de acuerdoss del mismo archivo. 
rias contra los judíos, la realidad, para el periodo comprendido entre los años 1468 a 1478 , es totalmente distinta en las relaciones con la población hebrea de la ciudad de Murcia y obispado de Cartagena.

El cabildo capitular cartaginense, en su doble condición de señor civil y eclesiástico (7), tendrá como preocupación constante la búsqueda de una gestión y administración cada vez más eficiente para lograr, de esta manera, una mejor dotación económica del propio cabildo y de sus miembros; para ello tratará de ampliar sus fuentes de ingresos y adaptarlas a la situación cambiante de la economla castellana en esta segunda mitad del siglo XV, sobre todo evitando su deterioro. Conforme con esta práctica serán numerosos los judíos (8) que ocupen puestos relevantes en la gestión económica del cabildo, ya como arrendadores de las rentas, ya como intermediarios en su recaudación.

Ahora bien, nos parece aclarar que este proteccionismo por parte de la Iglesia de Cartagena en pró de la población hebrea es referible tan solo al campo económico, pues en lo referente a las normas morales y de convivencia seguían practicándose las normas establecidas por la Iglesia general y diocesana (9), como se deduce de los sínodos diocesanos celebrados por don Juan de Medina y don Lope de Rivas. Del primero son las siguientes constituciones: $~ D D$ judeis et sarracenis. Que los cristianos no coman de sus viandas ni viuan con ellos e de las penas contrarium faciéntis"; "Que los carniceros cristianos no den a degollar a los moros ni judios la carne que an de uender a los cristianos». Del segundo: "Contra los que lleuan, dan o venden cosas vedadas a los moros y judios";

(7) In tanto que como corporación dotada de una personalidad jurílica y un derecho de propicdad autónomos gozaría de un cuantioso beneficio formado por toda una serie de ingresos, dercehos y privilegios.

(8) EI número de judíos que hemos encontrado en los documentos consultados es de 48, como aparecen relacionados al final del presente capitulo. Todos ellos desempeñando cargos referentes a la economfa cpiscopal y capitular.

(9) A.C.Mu. Cód. n० 236, f. 68r. y v.; 69r. y v. 
"Contra los que van a bodas e mortuorios o fiestas de los judios o moros». (10).

Antes de entrar en materia hemos de señalar que dentro de la organización económica del cabildo murciano en el siglo XV, en cuanto al sistema de recaudación de rentas, existían dos instituciones jurisdiccionalmente indepedientes: la mesa capitular y la mesa episcopal (11). Atendiendo a este primer indicio, y a la vista de lo contenido en las fuentes, podemos afirmar que los judios eran arrendadores tanto de la mesa capitular como de la episcopal, aunque encontraban un mayor beneficio en las rentas del obispo por causas que más adelante explicaremos. Encontramos también gran cantidad de rentas, tanto capitulares como episcopales, concentradas bajo la misma persona, lo que es indice de un pequeño monopolio de rentas por los judíos, tan influyentes en la vida económica de la Murcia del siglo XV, como son:

Ysaaq Aventuriel: arrendador del provisor e obispo en 1470. El mismo es arrendador de 12 raciones que el obispo tenía en Lorca.

Mosé Allori: arrendador en 1469 de las rentas del obispo en 160.000 mrs. pertenecientes a los años de $70,71,72,73,74$.

Symuel Botin: arrendador de las rentas de las tercias del alhama del obispo en 1472.

(10) Ver apéndice documental del presente trabajo.

(11) En relación a los casacteres de las rentas observamos una clara distinción en el reparto de las mismas entre las mesas episcopal y capitular, por cjemplo entre las tercias correspondientes al obispo y las correspondientes al cabildo; también entre las rentas decimales y señoriales. El rediczmo era solo del obispo y consistía generalmente en un noveno que se exigia de los frutos después de haber pagado el diezmo. 


\section{A) LOS ARRENDAMIENTOS A JUDIOS.}

$\mathrm{Ni}$ que decir tiene que, entre las formas de tenencia de las propiedades y rentas del cabildo capitular murciano en la segunda mitad del siglo XV, el arrendamiento es la fórmula económica más utilizada. El proceso seguido en su ejecución podemos describirlo de la siguiente manera:

En una primera fase la institución capitular, como colectivo, sólo interviene para sacar a subasta durante tres cabildos consecutivos las rentas provenientes del conjunto de propiedades que le pertenecen en todo el obispado (12).

Con esta subasta se inicia la segunda fase, en la cual se debe hacer el remate o adjudicación en favor de la persona que «más pujó»; pero ello no sin antes de que esta persona hubiese nombrado un fiador (13), que es el que tiene que responder en el caso de que el tomador del arrendamiento no abonase la renta a la que se había comprometido dentro de los plazos señalados (14).

En opinión de Rodríguez Villacorta (15) «cuando se adjudicaban estas rentas eran preferidos los beneficiados de la catedral, en primer lugar; después los clérigos del obispado y a continuación los seglares». Según estos nos encontramos que en el siglo XV, y más concretamente en el decenio de 1468 a 1478 parecen invertirse los términos

(12) Hacemos recaer sobre la palabra arentas el conjunto de todos los tipos de bienes, derechos y otros ingresos que constituían el patrimonio del cabildo, del obispo y de la fábrica de la Iglesia. Esto en la segunda mitad del siglo XV, que es la que estudiamos.

(13) En un principio el fiador debla ser un miembro del cabildo, pero conforme nos adentramos en la segunda mitad del siglo XV observamos que el fiador podía ser un seglar, siendo muy numerosos los judios que aparecen como fiadores en los contratos de arrendamiento capitulares.

(14) Martinez CARRILlo, M.* DE l.os L.L.: "L.as pujas del quinto en los arrendamientos de rentas en la segunda mitad del siglo XIV». En M.M.Mu. 12 (Murcia, 1985), p. 9-27; Ibidem.: “Rentas reales en los comienzos del siglo XV murciano. Arrendadores y recaudadoresm. En Murgentana 59 (Murcia, 1980), p. 37-56.

(15) Vil..Acorta Rodriguez, T.: «El cabildo de la catedral de León. Estudio histórico-jurídico. Siglos XIII-XJX». León, 1974. 
en lo que respecta al cabildo de la catedral de Murcia ya que los judíos acaparan en un primer lugar los puestos de arrendadores capitulares, según podemos constatar por la siguiente relación:

1) Arrendadores del carnaje.

Arrendadores

Mosé Allorí

Abrahim Abeniaçar

Yuçaf Botín

Symuel Botín

Ysaaq Dux

Año

1469

$1471-73$

1472

1473

1474
Lugar

Murcia

Lorca

Murcia

Campo de Cartagena

Murcia

2) Arrendadores de la renta del aceite.

Arrendador

Mosé Cohen
Año

1474
Lugar

Murcia

3) Arrendadores de la renta de las albabas (16).

Arrendadores

Abrahim Almateri

Symuel Botín

Abrahím Botín
Año

1468 (Cabildo)

$1471-72$ (Tercias obispo)

1472-73
Lugar

Murcia

Murcia

Murcia

4) Arrendadores de la sisa.

Arrendadores

Ysaaq Abolafia

Mosé Allori

Yudá Axaques

Mosé Abendarra
Anio

1474

1470

1469

1471
Lugar

Murcia

Murcia

Murcia

Murcia

(16) Alhabas: Unidad de medida aplicada al volumen de agua que se adjuclicaloa en un tiempo dado a una determinada porción de terreno agricola. 
5) Arrendadores de la miel y cera.

$\begin{array}{lll}\text { Arrendadores } & \text { Año } & \text { Lugar } \\ \text { Mayr Abendarro } & 1470 & \text { Murcia }\end{array}$

6) Arrendadores de los bigos.

$\begin{array}{lll}\text { Arrendadores } & \text { Año } & \text { Lugar } \\ \text { Ysaac Botín } & 1469-70 & \text { Murcia } \\ \text { Mosé Abenarroyo } & 1471 & \text { Murcia } \\ \text { Mosé Allorí } & 1472 & \text { Murcia }\end{array}$

7) Arrendadores de las pilas: se trata en apartado aparte.

8) Arrendadores del obispo.

Mosé Allor'

Abrahsm Aventuriel

Mosé Cohen (arrendador de la renta de lo que pertenece al obispo en la villa de Molina)

Symuel Borín.

Las rentas pertenecientes a la mesa episcopal seguian, para su adjudicación, el mismo proceso, subasta y puja, que las pertenecientes a la mesa capitular, pero con la salvedad de que estas quedaban bajo la tutoría del provisor y sólamente él podía arrendarlas a una segunda persona uen nombre del obispon. Por tanto los arrendadores de las rentas episcopales los encontramos tanto de forma individual como asociados entre sí. Cuando aparecen de forma individual, como ocurre en la mayoría de los casos, estos "tomadores del arriendo" pueden a su vez subarrendarlas o traspasarlas a otras personas, por los menos parte de esas rentas, como lo vemos en los siguientes casos:

Ysaaq Aventuriel «trespasó a Yssaq Auenturiel, su primo, una calongía del obispo por dos años, por el prescio e condiciones que él las tiene arrendadas". 
Mosé Allori utrespasó la mitad de las rentas del Alcantarilla e de las Alquerías que tiene arrendadas del obispo a Mosé Abenarroyo por el prescio e años que él las tiene arrendadas».

A la vista de esta posibilidad de subarriendo por parte del arrendador judio (17) nos inclinamos a pensar que dicha transación o traspaso reportaría alguna clase de beneficio al judio arrendador. A la vista de lo que nos dicen las fuentes observamos que cuando se realiza un traspaso se indica como coletilla «en el precio e años que él las tiene arrendadas"; pero la realidad, ajena o no a los intereses capitulares, y en este caso episcopales, debia ser bastante distinta. El judio arrendador abonaba al obispo, o en su caso al provisor, las rentas en los plazos señalados; este, a su vez, las subarrendaba, todas o parte de ellas, a una tercera persona, de la que recibia la cantidad pactada al momento de hacerse el traspaso, por lo que el judio, primer arrendador, se convierte en intermediario entre el cabildo u obispo y esa tercera persona, o segunda, a la que traspasa el arriendo. No se debe olvidar que el intermediario pagará al obispo o cabildo las rentas en plazos determinados, mientras que el arrendador, al hacer el subarriendo o traspaso, lo cobra al contado. Entre la forma de pago aplazada y el cobro al contado el judío que hace el traspaso verá aumentado su beneficio, dada la depreciación y fluctuación de la moneda en el siglo XV.

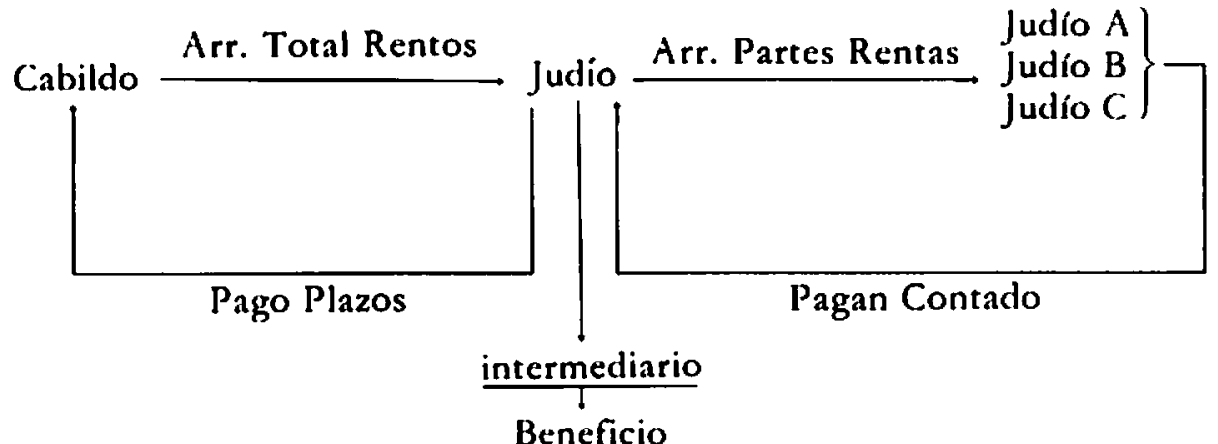

(17) Sólo hemos encontrado esta práctica del subarriendo en el caso de los judios, por supucsto en el caso de la lglesia, en la época que estudiamos. 
Nos confirma aún más esțe fenómeno el que la mayoría de las rentas episcopales fuesen arrendadas a largo plazo, es decir durante un periodo de uno o dos años como mínimo, o más, como es el caso de Mosé Allorí que "puso la renta de la obispalía de los años 71,72 , 73 y 74 en 160.000 maravedies».

A tenor de lo anteriormente dicho creemos poder afirmar que los judíos murcianos gozaban de una libertad de acción que les convertía en verdaderos prestamistas y capitalistas en una sociedad que no comprendia la función y el empleo del dinero como capital. En cierta manera estos judíos arrendadores del obispo y del cabildo murcianos practicaban la usura, a pesar de las severas penas con que el derecho canónico la prohibía a los cristianos en general, a los judíos y a los clérigos, y de las sanciones que los sínodos imponen a los usure$\operatorname{ros}(18)$.

Es curioso observar en las fuentes cosultadas cómo los judíos, que toman en arriendo de la mesa episcopal rentas y otros bienes, por el sistema mencionado de puja y subasta durante el plazo de uno o dos años, no aparecen en la misma situación con respecto a las rentas y bienes de la mesa capitular, por lo menos no lo hemos encontrado; en estas no hemos visto ningún caso de subarriendo. Quizás sea esto debido a la renovación casi anual de los contratos de arrendamiento por parte del cabildo, o tal vez al mayor control ejercido por sus miembros sobre la población hebrea. De todas formas hemos de señalar que las rentas y otros beneficios de la dicha mesa capitular eran, o por los menos estaban, más repartidas entre todos los componentes del cabildo que las rentas pertenecientes solo al obispo, por lo que jugaría un papel importante el factor cantidad a la hora de arrendar esas rentas y bienes.

(18) Constituciones sinodales de don Lope de Rivas y don Juan de Medina sobre la usura. Ver apéndice documental. 


\section{B) LA RENTA DE LAS PILAS.}

Es una renta que aparece muy frecuentemente en los códices y documentos consultados en el Archivo Capitular, concretamente en la época que estudiamos, y que pensamos se denominaban upilas» por su posible identificación con parroquias o feligresias; aparecen en la segunda mitad del siglo XV y se destinaban a la fábrica de la Iglesia de Cartagena, es decir como una contribución destinada a la obra de la catedral de Murcia.

Esta renta se obtenía de la percepción de los frutos de la quinta casa dezmera de cada ciudad, villa o lugar, según se deduce de la Bula de Benedicto XIII, 1416, sobre "como fueron aplicadas las pilas $y$ quintas casas dezmeras del obispado a la fábrica de la Yglesia Cathedal» (19).

El sistema de arrendamiento de estas rentas debió ser igual al utilizado para la adjudicación de las demás rentas elesiásticas -subasta y puja-, con la diferencia de que la renta de las pilas era adjudicada por el obrero de la fábrica de la Iglesia de Santa María la Mayor de Murcia: «...arrendó del obrero... ...las rentas de las pilas de... pertenecientes al año de...», expresión que se repite constantemente en este tipo de arrendamiento.

Una singularidad de estas rentas es que no aparece en ellas el traspaso o subarriendo a una tercera persona, como sucedía en los arrendamientos de las rentas episcopales, sobre todo con los arrendadores judíos, lo que puede indicar una postura más acertada de la Iglesia de Cartagena en su adjudicación. Ahora los arrendadores judíos aparecen no como intermediarios, sino como meros recaudadores de estas rentas.

(19) aSínodos del obispado de Cartagenaw. Iin A.C.Mu. Cód. s/n, f. 159v.-162v. 
RELACION DE ARRENDADORES DE LAS PILAS DEL CABILDO MURCIANO DEL S. XV

\begin{tabular}{|c|c|c|c|c|}
\hline & 1469 & 1470 & 1471 & 1472 \\
\hline MURCIA & Yuçaf Allori & & $\begin{array}{l}\text { Mosen Allori } \\
35.000 \mathrm{mrs} \text {. }\end{array}$ & $\begin{array}{c}\text { Provisor } \\
35.000 \mathrm{mrs} .\end{array}$ \\
\hline LORCA & & $\begin{array}{c}\text { Symuel Abendardi } \\
30.000 \mathrm{mrs} .\end{array}$ & & \\
\hline MULA & & & & $\begin{array}{l}\text { J. Guirao y Pedro } \\
\text { Ruiz. } 2.600 \text { mss. }\end{array}$ \\
\hline MOLINA & Maye Abendano & & & \\
\hline CIEZA & & & & David Abenatroyo \\
\hline \multicolumn{5}{|l|}{ ORJHUELA } \\
\hline VILLENA & $\begin{array}{l}\text { J. Rui y J. Tristan } \\
11.000 \text { mrs. }\end{array}$ & $\begin{array}{c}\text { Gonzalo Martinez } \\
12.600 \mathrm{mrs} . \\
\end{array}$ & $\begin{array}{l}\text { Fray Ferrando de } \\
\text { Almansa. } 12.700 \text { mrs. }\end{array}$ & \\
\hline \multicolumn{5}{|l|}{ JUMILLA } \\
\hline YECLA & & & Martin Martinez & \\
\hline LIBRILLA & Mayr Abendano & & & \\
\hline \multicolumn{5}{|l|}{ GUARDAMAR } \\
\hline \multicolumn{5}{|l|}{ AYORA } \\
\hline \multicolumn{5}{|l|}{ CAUDETE } \\
\hline \multicolumn{5}{|l|}{ ALICANTE } \\
\hline \multicolumn{5}{|l|}{ ELCHE } \\
\hline \multicolumn{5}{|l|}{ MONFORTE } \\
\hline AL.BACETE & & & & $\begin{array}{c}\text { Rodrigo de Albacete } \\
7.000 \mathrm{mrs} .\end{array}$ \\
\hline LA GINETA & & & & $\begin{array}{c}\text { Rodrigo de Albacete } \\
7.000 \mathrm{mr} \text {. }\end{array}$ \\
\hline MONTEALEGRE & & & $\begin{array}{c}\text { Benito Sanchez } \\
400 \text { mes. }\end{array}$ & \\
\hline ALPERA & & $\begin{array}{l}\text { Martin Martinez } \\
400 \text { mes. }\end{array}$ & $\begin{array}{l}\text { Benito Sinchez } \\
400 \text { mrs. }\end{array}$ & \\
\hline R. XORQUERA & & & $\begin{array}{l}\text { Pedro de Bailen } \\
7.000 \mathrm{mr} 3\end{array}$ & \\
\hline LAS PEÑAS & & & $\begin{array}{l}\text { Arcipreste de Chin- } \\
\text { chilla. } 8.800 \text { mrs. }\end{array}$ & \\
\hline CHINCHILLA & & & $\begin{array}{l}\text { Ascipreste de Chin- } \\
\text { chilla. } 8.800 \text { mrs. }\end{array}$ & \\
\hline
\end{tabular}




\begin{tabular}{|c|c|c|c|c|}
\hline & 1469 & 1470 & 1471 & 1472 \\
\hline MURCIA & $\begin{array}{c}\text { Mosen Allori } \\
35.000 \text { mrs. }\end{array}$ & David Abenaex & & \\
\hline LORCA & $\begin{array}{l}\text { lsaac Abeniatar } \\
30.000 \text { mrs. }\end{array}$ & David Abenaex & & \\
\hline MULA & $\begin{array}{c}\text { Maur Abendano } \\
3.000 \mathrm{mrs} \text {. }\end{array}$ & & & \\
\hline MOLINA & $\begin{array}{c}\text { Mosen Allori } \\
2.000 \text { mrs. }\end{array}$ & $\begin{array}{l}\text { Mosen Allori } \\
2.000 \mathrm{mrs} \text {. }\end{array}$ & & \\
\hline CIEZA & $\begin{array}{c}\text { J. Gomez de Astudi } \\
1.500 \mathrm{mrs} .\end{array}$ & & & \\
\hline ORIHUELA & $\begin{array}{c}\text { Geronimo Lopex } \\
70 \text { timbres }\end{array}$ & & & \\
\hline VILLENA & $\begin{array}{c}\text { F. Alfonso, notario } \\
7.467 \text { mrs. }\end{array}$ & & & \\
\hline JUMILLA & $\begin{array}{c}\text { Diego Thomss } \\
2.200 \mathrm{mrs} . \\
\end{array}$ & & & \\
\hline YECLA & $\begin{array}{c}\text { F. Alfonso, nolario } \\
7.467 \mathrm{mrs} \text {. }\end{array}$ & & & \\
\hline LIBRIL.LA & $\begin{array}{c}\text { Mayr Abendano } \\
1.000 \text { mrs. }\end{array}$ & & & \\
\hline GUARDAMAR & $\begin{array}{l}\text { Solet, canonigo. } \\
90 \text { sueldos }\end{array}$ & $\begin{array}{c}\text { J. de Ayora, diacono } \\
1.800 \mathrm{mrs} .\end{array}$ & $\begin{array}{l}\text { J. de Ayosa } \\
1.800 \text { mrs. }\end{array}$ & $\begin{array}{c}\text { J. de Ayora, dizcono } \\
1.800 \text { mss. }\end{array}$ \\
\hline AYORA & $\begin{array}{c}\text { Luis Gonzslez, } \\
\text { sjeaide. } 2.800 \text { mrs. }\end{array}$ & & & \\
\hline CAUDETE & $\begin{array}{l}\text { Luis Gonzilez, } \\
\text { alcaide. } 2.800 \text { mss. }\end{array}$ & & & \\
\hline ALICANTE & $\begin{array}{l}\text { Alfonso Fernandez } \\
\text { I30 reales cat. }\end{array}$ & & & \\
\hline ELCHE & $\begin{array}{l}\text { Alfonwo Fdex, canon. } \\
130 \text { reales cat. }\end{array}$ & & & \\
\hline MONFORTE & $\begin{array}{c}\text { Alfonso Fdex, canon. } \\
130 \text { reales cat. }\end{array}$ & & & \\
\hline \multicolumn{5}{|l|}{ ALBACETE } \\
\hline \multicolumn{5}{|l|}{ LA GINETA } \\
\hline \multicolumn{5}{|c|}{ MONTEALEGRE } \\
\hline \multicolumn{5}{|l|}{ ALPERA } \\
\hline \multicolumn{5}{|l|}{ R. XORQUERA } \\
\hline \multicolumn{5}{|l|}{ LAS PENAAS } \\
\hline CHINCHILLLA & & & & \\
\hline
\end{tabular}


Observando el gráfico adjunto se puede apreciar cómo la presencia de arrendadores judíos se acentúan en torno a Murcia, Lorca, Mula, Cieza y Librilla, no apareciendo ninguno de esta raza en la demarcación territorial del Señorío de Villena (20): Villena, Yecla, Ayora, Caudete, Monforte, Albacete, La Gineta, Montealegre, Alpera, Las Peñas y Chinchilla. En estos lugares de señorío los arrendadores de las pilas serán vecinos de la villa (Albacete, La Gineta, Xorquera) o alcaides (Ayora y Caudete) o notarios (Villena) o arciprestes, clérigos y rectores de las iglesias o parroquias (Chinchilla, Las Peñas, Alpera y Montealegre).

Pensamos que este hecho puede ser debido a diversas circunstancias:

a) Que la disponibilidad judía a tomar en arriendo las rentas de las pilas fuese acompañada de una cierta predilección por los lugares donde ellos tenían aljama (Murcia, Lorca, Mula).

b) Que la densidad de población -debido al incremento demográfico que se produce en Castilla en el siglo XV -es mayor en Murcia, Lorca, Mula etc, que en los lugares y villas del marquesado de Villena, con lo cual la recaudación de las pilas sería más cuantiosa y mayor en aquellas que en estas.

c) Que la Iglesia de Cartagena quisiera tener más vigilada la acción de estos judíos en el recaudamiento de las pilas, dado el fin a que se destinaban.

Vemos, por otra parte, confirmando lo dicho en los apartados B. y $C$., que los precios en que se arrendaban las pilas eran mayores en Murcia, Lorca, Molina, Mula, Cieza y Librilla que los que se daban en

(20) TORRES FONTES, J.: al.a conquista del marquesado de Villena en el reinado de los Reyes Ca-

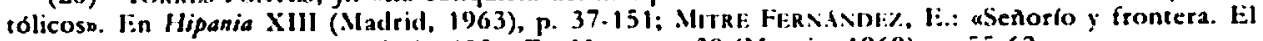
marquesado de Villena entre 1386.1402w. En Murgesana 30 (Murcia, 1969), p. 55.62 
los lugares del señorio de Villena. Por lo que respecta a la moneda en que se cobraban dichas rentas hemos de poner especial atención en el caso de Orihuela, perteneciente al reino de Aragón, donde se cobraba una moneda llamada "timbre» (21), en el resto de la diócesis, que era castellana, se cobraba en maravedies, dentro de las diversas fluctuaciones que su valor, en oro y plata, tuvo a lo largo de la segunda mitad del siglo XV.

Finalmente hemos de hacer mención al sistema utilizado por los arrendadores judíos de las pilas, para lo que tomaremos como punto de partida el año 1473. En este año, en la reunión capitular de 27 de febrero "Mosé Allorí arrendó las pilas de esta ciudad en el precio de treinta y cinco mil maravedies». En el mismo año, en la sesión del 6 de abril, "Abrahín Auenturiel demandó a Mosé Abenarroyo por cuanto él habra sacado las pilas de esta ciudad en este año la cuarta parte, e pasó de darle su parte y trabajo en ello». Más adelante, dentro del mismo año aparece Abrahín Auenturiel como arrendador de las pilas de Murcia, señalando "que él tiene por pila en la collación de Santa Catalina a Sancho Gómez de Arroniz» (22).

Conforme a lo señalado por las fuentes podemos, pues, llegar a las siguientes conclusiones:

a) Que bajo un mismo arrendador aparece el arrendamiento de la totalidad de las pilas de la ciudad de Murcia, el cual se compromete a pagar lo pactado y pone fiadores.

(21) Moneda de oro en la Corona de Aragón acuntada para competir con el florín y caracterizada por tener en el reverso el escudo timbre de Aragón (yelmo y cimera en forma de cabeza de dragón). En 1394 Juan I acunó en Perpignan el llamado timbrc de Aragón, que lleva en el anverso el rcy de cuerpo entero de posición mayestática. Su valor era de 23 y $1 / 4$ quilates, 58 y $1 / 2$ piczas cn marco y pesaba 405 grs., valia 1'636 forines y equivalia a 18 sueldos de dineros barceloneses. En 1426 Alfonso el Magnánimo aunó el timbre de Valencia, como moneda primitiva de este reino, con el escudo borrado en el anverso; su valor era de 10 monedas de dineros valencianos. A ambos el florín los expul. só del mercado.

(22) A.C.Mu. l.ibro de Prot. cit., f. 184v.; 193r. y 188v. etc. 
b) Una vez arrendadas la totalidad de las pilas, y previa licencia de la Iglesia de Cartagena, este primer arrendador repartirá el recaudamiento de las dichas rentas en cuatro secciones, divididas por parroquias, a otros recaudadores.

c) Estos subarrendadores pagarán lo obtenido en la recaudación al que tomó la totalidad de las rentas de las pilas; al mismo tiempo que estos cobrarán una cantidad determinada por su trabajo de «recoger» dichas rentas por parte del arrendador de la totalidad de las mismas.

Naturalmente se trata de una interpretación personal que hacemos de las fuentes, que pueden ser objeto, pues la materia es abundante, de estudios más minuciosos y profundos.

\section{C) LOS JUDIOS Y LA JUSTICIA CAPITULAR.}

La mayor parte de las medidas sobre administración del patrimonio capitular promulgadas a lo largo del siglo XV se encuentran recogidas fundamentalmente en los libros de actas capitulares de este siglo, en los sínodos diocesanos de la época, en algunos legajos sueltos $y$, sobre todo, en un códice conteniendo los protocolos del notario Juan Sánchez de Santisteban que abarca los años de 1468 a 1473, ambos inclusive (23).

Casi toda la legislación y normas contenidas en las mencionadas fuentes van encaminadas a poner en práctica la normativa eclesiástica ya promulgada con anterioridad, pasando de una legislación de tipo general (siglos XIII y XIV) a otra más particular y concreta (finales del siglo XIV y siglo XV). Durante el siglo XV se vá a producir un importante cambio, pues se vá tomando conciencia de la problemática

(23) Ib. Libro de Protorolos o Notas de Juan Sanchez de Santisteban, notario público de Murcia. Papeles cocantes al cabildo de 1468 a 1473 , Cód. B.2.: aSinodales del obispado de Cartagena. Siglos XIV y XV. Códices No 206, 213, 236, 237, 258 y 259. 
en que se desenvolvían las relaciones del cabildo catedral con los arrendadores de sus bienes; se desciende, pues, a lo particular, a cada caso concreto, al terreno en el que realmente se encontraban los problemas.

Buena prueba de todo esto es la constatación, al examinar las fuentes, de la cantidad de pleitos que el cabildo murciano, concretamente en el decenio 1468-1478, mantiene con sus arrendadores, en especial con aquellos que pertenecian a la población hebrea. En una visión rápida sobre la organización capitular, en cuanto a la administración de la justicia se refire, podemos puntualizar lo siguiente:

El cabildo, como órgano jurídico autónomo, se reunía en ucabildo ordinario" tres días por semana, generalmente los lunes, miércoles y viernes, para tratar, entre otras cosas, los pleitos que surgían respecto a sus propiedades, bienes y rentas. A la cabeza, como juez de la institución, estaba el provisor, que presidía todas y cada una de las sesiones capitulares, acompañado siempre de un secretario-notario que levantaba acta de lo tratado y el asunto de los pleitos que se presentaban. Asistían, además, un número reducido de capitulares, normalmente las dignidades y algunos simples canónigos que tenían voz y voto a la hora de aprobar o desestimar la cuestión llevada a la presencia del provisor. Con ellos se encontraban también los procuradores que representaban a la parte que udemanda o apela», así como un grupo de testigos, clérigos y seglares vecinos de Murcia, que deben estar presentes para dar fé de lo allí sucedio.

Es a la persona del provisor a quien van dirigidos cada uno de los asuntos a tratar, de aquí que siempre las actas comiencen: «Este dicho dra paresció antel señor provisor...». Como juez será él quien dicte las sentencias, prorrogue la presentación de testigos, tome «juramentos de calupnia», fé de los contratos de arrendamiento, otorgue cartas de pago, de cartas executorias, cartas de edicto etc. 
Dada esta visión general diremos que los judíos, desde el momento en que se relacionan con la vida capitular, o mejor diocesana, como arrendadores del cabildo y del obispo, se obligan a someterse a la justicia eclesiástica (24). Los litigantes se sirven, generalmente, de un procurador, de ordinario algún miembro del cabildo (25), para resolver sus pleitos ante el provisor y someterlos a la justicia capitular, que debe actuar como un neutral intermediario: "Este dicho dia paresció antel prouisor Alfonso de Santa María (26) en nombre de Botín, judío...». Por su parte el judio había de dar su "poder cumplido», por escrito, a la persona que iba a actuar como procurador suyo: "Este dicho dia David Auenturiel, judío, dió su poder cumplido a Alfonso de Santa María, absente, para en todos sus pleitos, acciones e demandas que él ha o espera auer, e otras contra él, e para pedir sentencias e apelar e consentir e fazer qualesquier juramentos..." (27).

También encontramos casos en que los judíos nombraban como procuradores suyos a otros de su misma raza: «Aquín Jahenía en nombre de Abrahín el Rotín...», lo que nos lleva a pensar en ciertos privilegios que algunos judíos - generalmente los más relevantes en el status social hebreo- gozaban dentro de la organización juridica capitular: «Ysaaq Manduz acusó la rebeldía al canónigo Diego Rodríguez de Almelay (28), e incluso nos encontramos con casos en que los judís, cuando son agraviados por personas de la Iglesia de Cartagena recurren al provisor del obispado para que haga ulo que en justicia deue».

Según esto podemos afirmar, quizás sin temor a equivocarnos, que la legislación capitular de la Iglesia de Cartagena en la segunda mitad

(24) Así se especifica en los contratos de arrendamiento.

(25) Los nombres que se citan actuando como tales durante cstos anoos son: Alfonso de Santa Maria $y$ Ferradianes; al parecer, por lo que se deduce de sus actuaciones, fueron my eficicntes en el cjercicio de su procuración.

(26) ¿Pariente de don Pablo de Santa María? Parece que si por la coincidencia cronológica. Libro de Prot, cit., f. 169r.

(27) A.C.Mu. Libro de Prot. cit., codd. B.2., f. 27.; 29v.; 59v.; 68. etc.

(28) Ib., f. 208r.; 69r.; 162r. etc. 
del siglo XV era muy condescendiente con la población judía, permitiéndole una serie de derechos que, en definitiva, no serían muy corrientes en el resto de los cabildos castellanos, según las monografias que al respecto hemos leido (29), y menos en esta etapa próximos a su expulsión, de España por los Reyes Católicos en 1972. Debemos añadir que los pleitos sostenidos por los judíos con el cabildo catedral son en su mayoŕa de matiz económico, demandas por pagos de rentas, demandas de pagos por venta de paños de los miembros del cabildo etc. (30), lo que nos induce a pensar, como antes apuntábamos, en cierto proteccionismo de los judíos por parte de la justicia capitular, sobre todo en lo que a economía se refiere (31).

D) GENOVESES Y JUDIOS.

Según el profesor Torres Fontes la presencia de mercaderes italianos en el Reino de Murcia se remonta al siglo XIII (32), en que estos ya matenían una próspera actividad comercial con los musulmanes murcianos desde la expulsión de los almohades. En el siglo XV, con la llegada al Trono de los Trastámara, se produce un elevado desarrollo a todos los niveles de la vida ciudadana en Murcia, en la que, de

(29) Entre otros, podemos citar a: Vil.t.Aconta, T.: alil cabildo de la Catedral de León. Siglos XII-XIX. Estudio histórico-jurídicom. En Fuentes y estudios de Historia leonesa 12. León, 1974. CASADO, Alonso, H.: al.a propiedad eclesiástica en la ciudad de Burgos en el siglo XV: el cabildo catedralicion. Valladolid, 1980. MARTiN, J.L.: aEl cabildo de la catedral de Salamanca. Siglos XII-XIll». Salamanca, 1975. Lopl:z. ARtval.O, J.R.: aUn cabildo catedral de la Vieja Castilla. Avila: su estructura juridica. Siglos XII]-XX". Madrid, 1966. SANCHEZ HtRRI:RO, J.: “Vida y costumbres de los componentes del cabildo catedral de Palencia a fines del siglo $X V \mathrm{~V}$. lin Historia, Instituciones y Documentos 3 (Sevilla, 1976). Sax Martix Payo, J.: aEl cabildo de Palencian. En Public. de la Instifusión Tello Tellez de Manesess, n.o 34, 1974. Barroos Garcia, A.: al.a catedral de Avila en la Edad Media: estructura, sociojurídica y económicas. Avila, 1973.

(30) A.C.Mu. I.ibro de Prot. cit., f. 41r.; 33v.; 78.; 169r.; etc.

(31) Son muy frecuentes los acasos de rebeldias: aAcusó la relbeldías. Rebeldía, scgún cl Derecho Procesal, es la situación del demandado, imputado o procesado que no comparece en la avistay en los juicios o no se persona en los autos y requerimientos del jucz.

(32) TORhi:s FoNTI:s, J.: aGenoveses en Murcia. Siglo XVw. En M.M.Mu. Il (Murcia, 1976), p. 69.168 . 
alguna manera, influye el establecimiento, con carácter permanente, de estos mercaderes italianos.

La Iglesia de Cartagena, y más concretamente el cabildo capitular, se adapta -al igual que el concejo- a las nuevas corrientes de expansión y florecimiento socio-económico de la sociedad murciana de la Baja Edad Media, a pesar de las normas morales instituidas -dada su condición- que le impedían participar en determinados asuntos de carácter económico y comercial.

Si la presencia de la población hebrea en la gestión económica del cabildo catedralicio es importante en esta segunda mitad del siglo $\mathrm{XV}$, no lo es menos la presencia de mercaderes italianos, sobre todo genoveses (33). Ambos, judíos y genoveses, mantendrán unas relaciones económicas y comerciales en las que el cabildo tiene un protagonismo especial; por una parte, este actúa como mediador en la resolución de sus pleitos, y por otra, como beneficiario indirecto de un comercio entre judíos y genoveses centrado en los paños.

Por lo que respecta a la legislación capitular observamos gran número de demandas efectuadas por genoveses ante el provisor reclamando el pago de ciertas cantidades de dinero que debían los judíos. Así el caso de Ysaaq Botín, que fué condenado por el provisor a que pagara a Juan Bautista Spindola, genovés, 2.8000 maravedies de dos blancas que "conoció deberle al dicho judío" (34), o el caso de Mosé Cohen y el maestro Daniel Lambahi, judios, que fueron condenados por el vicario de la diócesis a pagar a Juan Bautista Espindola, genovés, 6.552 maravedies, los cuales "conocieron deberle por un conocimienton (35).

(33) Lista de genoveses relacionados con el cabildo de Murcia: véase lista de ellos al final del capitulo.

(34) A.C.Ms. L.ibro de Prot. cit., f. 158r.

(35) Ib., f. 171v. 
A la vista de estos hemos podemos preguntarnos el por qué estos genoveses acudían al provisor para demandar a los judíos, pudiéndole hacer mediante la justicia seglar.

Para dar respuesta a esta pregunta nos formulamos tres hipótesis:

a) Que los genoveses estuvieron sometidos a la jurisdicción eclesiástica por algún motivo.

b) Que los judíos demandados se encontraran en esos momentos -como arrendadores de las rentas capitulares- sometidos a la jurisdicción eclesiástica.

c) Que los judíos demandados actuaran como intermediarios de cierta actividad comercial -si así puede llamársele- del cabildo con los genoveses.

En cuanto a la hipótesis a) no podemos asegurar nada, puesto que en las fuentes no aparece reflejado el que dichos genoveses se sometiesen a la jurisdicción eclesiástica por motivo alguno. Respecto a la hipótesis b) puede darnos alguna luz, pero no del todo cierta, ya que si los judíos mantenían cierta actividad comercial, por su parte, con los genoveses -independientemente de que fueran o no arrendadores del cabildo- estos deberían solucionar sus pleitos "de lego a lego" y para ello acudirían a la justicia civil y no a la eclesiástica. En cuanto a la hipótesis c) es la única que nos puede dar respuesta a la pregunta formulada. Confirma aún más esta hipótesis el gran número de demandas hechas a clérigos y canónigos directamente - sin la intervención judía- por mercaderes italianos, en especial genoveses (36).

Por otra parte, en lo concerniente al desarrollo de esta actividad comercial, en la que el cabildo murciano participa indirectamente, se centra sobre todo en el comercio de paños y sedas. Son numerosos los casos en que genoveses demandan el pago de ciertos paños, vendi-

(35) Ib., f. 171v.

(36) Ib., f. 193v.; 189r-189v.; 187v.; 186r.; 185v.; 182v.; 165r.; 162v.; 128r. ctc. 
dos a judios, ante el cabildo (37); al mismo tiempo que son también numerosas las ventas de paños tanto de parte judía, al cabildo, como de parte del cabildo a los judíos (38), lienzo, estopa y lino principalmente. En este caso último es significativo el caso de un clérigo que pide licencia al provisor para vender prendas de seda de Yuzaf Allorí, judío.

Ante esta realidad no nos cabe duda alguna de que cierta actividad de tipo comercial se desarrollaba entre ambos. Es más, observamos cómo es el propio cabildo el que unegocia» con los mercaderes genoveses la venta de productos de sus graneros, sobre todo trigo (39), sin intermediación judía.

Son también interesantes los casos en los que el cabildo murciano, por mediación judia, mantiene actividad comercial con lugares de fuera del Reino de Murcia, y por supuesto "extralímites» de la delimitación del obipado de Cartagena, en esta segunda mitad del siglo XV. Es el caso de Ysaaq Almateri, que fué demandado por Lope Cascante, "clérigo" "por quanto él dixo que se ovo obligado de traer de Valencia tres bonetes negros dobles, finos e nuevos, e que el dicho judio no los traxo, antes los traxo viejos e adoblados» (40). También se da esta actividad comercial con Almería: "Tomaron juramento a Yuma Isdrael, el qual dixo que leyó una carta de Amete Alcadí, vecino de Uera, por la qual exemía a Yuma Castel, por quanto le aúa dado azucar para que le truxere paño en aquel precion.

En resumen, podemos concluir diciendo que si es cierto que tanto judíos como genoveses obtuvieron grandes beneficios en base a su comercio, el cabildo murciano de la segunda mitad del XV no desaprovechó la ocasión para "cambiar» sus productos -recogidos de rentas y diezmos- por otras nuevas mercancías que los más altos estractos de la sociedad murciana de la época demandaban.

(37) Ib., 171v; 159r.; 118r.; 177r.; 158r.; 128r. etc.

(38) Ib., $33 \mathrm{v}$; 41 r.; $60 \mathrm{v}$.; 169 r. etc.

(39) Ib., f. 181 r.-v; 182r. etc.

(40) Ib., f. 195r,; 212v.; 313r. ctc. 
En otro orden de cosas, y dentro del tema que tratamos, hemos de hacer referencia a la importancia que adquieren tanto judíos como genoveses en el oficio de prestamistas dentro de la Iglesia de Cartagena. En la sesión del cabildo de 15 de julio de 1471 encontramos una obligación de pago por parte del arcipreste de Hellín a Juan Rótulo, genovés, de 5.000 maravedies «los quales le prestó por le fazer buena obray (41). Naturalmente que en este caso no sabemos si la cantidad prestada fué de 5.000 maravedies, o, por el contrario, la cantidad fué menor y con los intereses sumó los 5.000 maravedies; pero es curioso la coletilla final «le prestó por le fazer buena obra» eNo sería esta una forma de encubrir usura, tan castigada por la Iglesia, pero practicada por judios y genoveses con harta frecuencia?. Lo cierto es que la Iglesia murciana pasaría - consciente o no- por hechos tan claros y frecuentes de práctica de usura dentro de su propia organización. También en sesión del cabildo de enero de 1471 (42) el Maestre David, cantero, conoció recibir prestados de Symuel Botín, judío, 6.000 maravedies, y este se obligó a su vez a pagar estos maravedies al provisor en nombre de Botín.

Que la Iglesia, en general, estaba en contra de la usura es evidente como se deduce de la bula de Benedicto XIII de 1415 atambién que usan otros de tal cautela que no temen exigir de sus deudores el firmar contratos, en que figuren mayores cantidades que las realmente recibidas, mientras imponen a los cristianos bajo juramento, la obligación de cumplir tales contratos, no sin forzarlos a reconocer las deudas ante algún juez eclesiástico, confesándose merecedores de sentencia de excomunión, en caso de insolvencias. E igualmente lo estaba la Iglesia de Cartagena como se desprende de los capitulos sinodales de los obispos murcianos del XV, por ejemplo los de don Lope de Rivas

(41) Ib., f. 132r. Hay también numerosos casos de deudas contraidas por clérigos con genoveses, llegando incluso al embargo de sus bienes. Ib., f. 201 r.; 185v.; 182v.; 186r.; $193 v$. ctc.

(42) Ib., f. 112 r. 
«De usuris e de las penas de los usureros» o "Contra los clérigos usureros» etc (43).

Ante esta situación podemos hacer dos precisiones acerca del ejemplo arriba citado:

a) Que el judío en cuestión dispone de una cantidad de dinero que no le pertenece, pero a la que tiene acceso, en este caso concreto, como posible recaudador del provisor.

b) Que el dicho Maestre David recibió el dinero de manos del judío en concepto de préstamo y no por otro motivo.

A tenor de todo esto podemos pensar en la libertad que tenían los judios para usar o disponer de los fondos capitulares del cabildo murciano en su propio beneficio, con conocimiento del propio cabildo. Es más, nos inclinamos a pensar que estos judíos actuaban como banqueros capitulares durante toda esta segunda mitad del siglo XV, ya que no solo prestaban, sino que incluso cambiaban moneda, de donde el que se les denominara con el calificativo de "cambiador" (44). Es interesante, en este sentido, la compra que hace Ysaaq Abenaços, judío, a los herederos de Isabel Ramirez (45) -compra blacas viejas a dos blancas y media cada una- bajo la presencia del provisor, lo que nos muestra de forma más precisa su oficio de banqueros y la confianza puesta por el propio cabildo en la gestión económica de los judíos sobre las finanzas capitulares.

Son también frecuentes los pagos a terceras personas hechas por judíos «en nombre del deán e cabildo» (46), o de casos en que los ju-

(43)Amaixok de los Rlus, J.: o. c., ap. doc., p. 979 y s. También en A.C.Mu. Cod. s/n, f. $15 \mathrm{v},-162 \mathrm{r}, \mathrm{y}$ cód. no $236, \mathrm{f}, 70 \mathrm{v},-71 \mathrm{r}$.

(44)lb., f. 90r. (Acusamiento de rebeldía a Almaterí, cambiadoro).

(45) ib., f. $80 \mathrm{v}$.

(46) Ib., f. $101 \mathrm{v}$. 
díos embargan bienes a terceras personas con objeto de recuperar cantidades de dinero que se les deben (47).

Diremos, para terminar, que los judios fueron en esta etapa, hasta su expulsión, los prestamistas del pobre y los usureros de la sociedad murciana del siglo $\mathrm{XV}$.

\section{E) LA IGLESIA ANTE LA CONVIVENCIA DE JUDIOS CON CRISTIANOS.}

Si bien es verdad que la población hebrea de finales del siglo XV gozó de ciertos privilegios por parte de la Iglesia murciana, concretamente del cabildo capitular, no es menos cierto que se aplicaron rigurosas medidas por las que se prohibieron algunas de sus actividades en la convivencia con la población cristiana.

Observemos, pues, en este punto una doble postura por parte del cabildo respecto a los judíos. Por una parte era el propio cabildo quien otorgaba plena libertad a los judíos para hacerse cargo de su getión económico-administrativa capitular -como hemos podido constatar en apartados anteriores- haciendo caso omiso de las ordenanzas que contra ellos y sus actividades se promulgaron a lo largo del siglo $\mathrm{XV}$, asi como de las constituciones sinodales diocesanas (48), mientras que por otra parte se mostró inflexible en el cumplimiento de ciertos capitulos antijudíos sobre sus relaciones con los cristianos en

(47) Ib., f. 183r.

(48) Bula de Bencelicio XIII de 1415: en A.C.Mu. Cód. s/n, f. 159v-162r. También en AM.ABoR DE LOS RIOS, J.: o. c. ap. doc. no 20, p. 979 y s. Id. en cod. 236, f. 68r.69v.: aContra los que van a bodas, defunciones y fiestas de los judiosn; aContra los que llevan, dan o venden cosas vedadas a los judiosa (Sínodos de don l.ope de Rivas); aQue los cristianos ni vivan con los judios ni coman de sus viandasn; aQue los carniceros cristianos no den a los judíos a degollar la carneo (Sínodos de don Juan Medina). 
la coexistencia diaria (49), siempre que sus actividades "perjudicasen» el sentimiento cristiano del pueblo bajomedieval (50).

A temor de esto podemos afirmar que de las ordenanzas antijudias promulgadas en el siglo XV el cabildo capitular murciano solo llevó a la práctica aquellas en las que la gestión económica no se viera mermada. En efecto, partiendo de las fuentes encontramos una serie de ordenanzas y constituciones que, aunque dirigidas a la población cristiana, afectan a la población judía y coartan su actividad. Como ejemplo de tales ordenanzas citamos, entre otras, las siguientes:

Ordenanza a los fieles del granero mayor para que no se consienta hacer "el vino casser» de los judíos en sus graneros (51). Esta ordenanza aparece fechada en la sesión capitular del 29 de septiembre de 1478, pero nos queda constancia de que su promulgación fué anterior: «...e como traspasadores e quebrantadores de una ordenanza que los dichos señores tenían ordenada dias ha pasados...", lo que nos confirma en cierta arbitrariedad por parte del cabildo capitular a la hora de poner en práctica ciertos "mandatos» en contra de la población judía. Arbitrariedad que en este final del sigloXV parece verse vedada no porque el cabildo en sf mismo lo deseara, ya que fueron muchos los judíos que tenían acceso a la producción vinícola del granero mayor (52) y, por tanto, tenían oportunidad de fabricar su vino en el dicho granero utilizando los caldos recaudados por el cabildo en razón de rentas y diezmos, sino porque la situación moral de la pobla-

(49) Ilablamos de coexistencia, pues eran muchos los judios que compraban y adquirian casas fuera de la juderia, mezclándose con la población cristiana, por ejemplo el judio David Sauco y otros, y viceversa: Libro de Prot. cit., f. 160r.; 208v.; 209r.; 200r.; 121 v.; 76v. etc. También el Prof. To. RRES FONTES, J.: nos habla de cierta coexistencia entre judíos y cristianos en época florecientes y prósperas: en al.os judíos murcianos.... o. c., p. 64.

(50) Ribera Ri:CIO, J.F.: aEspiritualidad popular medievalı. En Hisforia de la espiritualidad, vol I (Barcelona, 1969), p. 610.660.

(51) A.C.Mu. al ibro vicjo de acuerdos (1455-1494)m, f. 54v.-55v. Que ninguno de los dicbos fieles non fuere osado de fazer en los dicbos graneros nin consintiesen a los judios fazer vino judiego, que se llama cas. ser......

(52) A.C.M. Libro de Protoc. cit., f. 141.; 86v.; 87.; 95v.; 142r. etc. 
ción murciana de este final de centuria parecia verse dañada «han hecho este año presente el tal vino judiego o casser en grand menosprecio de la christiandad e en grande escándalo del pueblo...». Así, pues, el cabildo tomaba ciertas medidas no por defender sus intereses económicos, sino por salvaguardar el aspecto moral de la población cristiana.

Ordenanza «contra los que van a sus bodas, defunciones o fiestas's. das».

Ordenanza «contra los que les llevan, dan o venden cosas veda-

Ordenanza «contra los carniceros cristianos que les dan a degollar la carne».

Ordenanza para que «ni vivan con los cristianos ni coman sus carnes ni otras viandas" etc.

Es cierto que si durante el siglo XIV y comienzos del XV son numerosas las concesiones de licencias para el ejercicio de la medicina a físicos y cirujanos judíos, dada la gravedad de las epidemias en la ciudad (53), en la segunda mitad del siglo XV, una vez recuperada la población y pasado el peligro, serán numerosas las sustituciones de ffsicos y cirujanos judios por cristianos. Así en la sesión capitular del 8 de mayo de 1470 el cabildo acuerda hacer gracia de 2.000 maravedies más de salario a un médico traido de Alicante para curar a los moradores cristianos, ya que «era mejor cosa tener físico christiano que non judío por quanto los derechos vedavan que ningund christiano non tomase medicina de mano judias (54). Medida que no solo es to-

(53) Jokres Fontrs, J.: aTres epidemias de peste en Murcia en el siglo XIV: 1348-49, 1379-80, 1395-96. En Rev. Medisa murciana II, las epidemias. Acad. Alf. X el Sabio. Biblioteca de loolsillo, 21 ,
1981 .

(54) A.C.Mu. Libro vicjo, c., f. 32 v. 
18

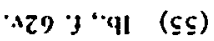

(e!วנnN) SGYVNGgV wечEมqV

(e!ว.nW) TGLVNGgV p!nea

(e!oun) GdחTNGgV jeSn $X$

(e!osnj) (osas!s) Vy

(e!วanN) S 5 XVANGgV ueyesqV

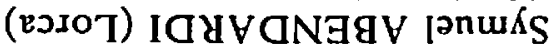

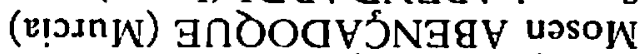

(e!JunN) SOŚVNGgV bees $X$

(ol!H) (eכIo)) y VSVINGg bees $\lambda$

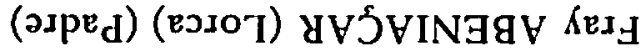

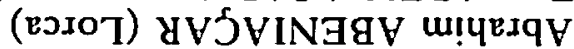

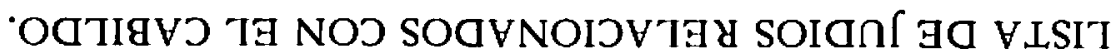

(૬ৎ) «enbse $\mathrm{d}$ ns so exoye

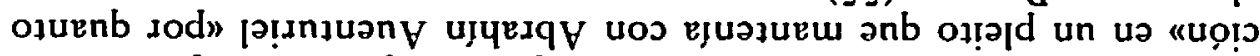

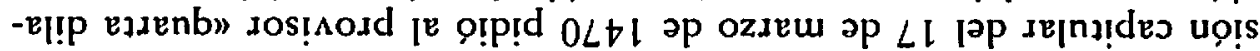

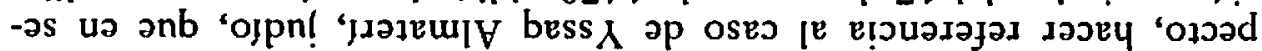

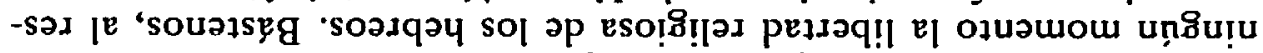

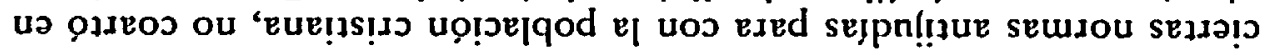

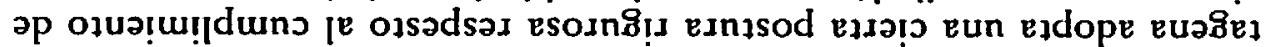

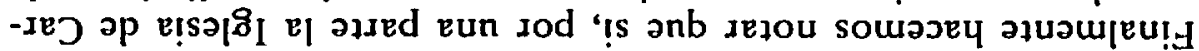

'

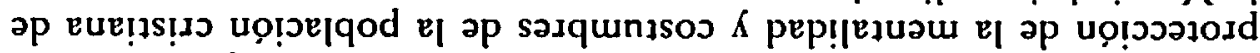

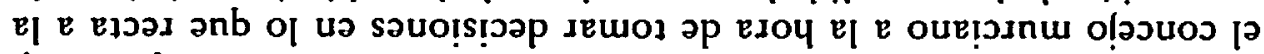

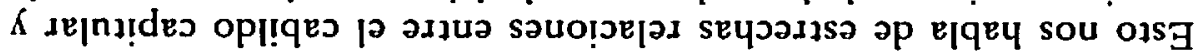

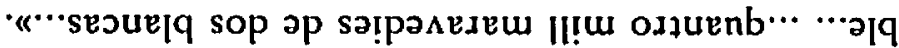

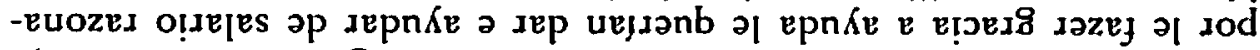
oləouos ן

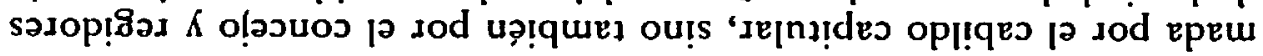


Ysaaq ABENARES (Murcia)

Dauid ABENARROYO (Cieza)

Estrug ABENARROYO (Cieza)

Ferrand ABENARROYO (Cieza)

Jahinda ABENARROYO (Cieza)

Symuel ABENARROYO (Cieza)

Yuda ABENARROYO (Cieza)

Rabi ABENASFE (Murcia)

Symuel ABENCRESPO (Murcia)

Dauid ABENDANO (Mula)

Mayr ABENDANO (Mula)

Mayr ABENDANO, el mayor (Mula)

Mosen ABENDANO (Mula)

Yuçaf ABENIUGA (Murcia)

Estrug ABENIANO (Lorca)

Symuel ABENIANO (Lorca)

Mosen ABENSYMON (Murcia)

Abrahim ABENTURIEL (Murcia)

Dauid ABENTURIEL (cedacero) (Murcia)

Mayr ABENTURIEL (Murcia)

Salamon ABENTURIEL (Murcia)

Ysaaq ABENTURIEL (Murcia)

Symuel ABOLAFIA (Murcia)

Ysaaq ABOLAFIA (Sisero) (Murcia)

Ysaaq ABRENALLA (Murcia)

Symuel ALLORI (Murcia)

Yuçaf ALLORI, el Chico (Pilero) (Murcia)

Abrahim ALMATERY (Murcia)

Ysaaq ALMATERY (Murcia)

ASTINGO (Murcia)

Yahuda AUDALO (Murcia)

Ysaaq AXAQUES (Murcia)

Yuda AXAQUES (sisero) (Murcia)

Dauid BENLAHID (maestre) (Murcia) 
Çaqueo BITON (Murcia)

Symuel BOTYN (Murcia)

Ysaaq BOTYN (Murcia)

Yuçaf BOTYN (Murcia)

Mosen BUENADOQUE (Murcia)

Yuda BUENAFE (Murcia)

ÇAMAYA, el Pincho (Murcia)

Symuel ÇALEMA (Murcia)

ÇALEMA CARDINAL (Murcia)

Yçaca ÇALEMA (Murcia)

Ysaaq CASTAL (Murcia)

Symuel COHEN (Murcia)

Yuçaf DAÇA (Murcia)

Abrahim DALUA (Murcia)

Ysaaq DUX (Murcia)

Jacob HELLI (Murcia)

Ysaaq FRANCO (Murcia)

Yuma ISDRAEL (Murcia)

Aquin JAHENY (Murcia)

Haquey JAHENY (Murcia)

Yçaque JAHENY (Murcia)

Dauid LANBAHI (Murcia)

Yuçaf EL LEVI (Lorca)

Symuel MALEQUI (Murcia)

Ysaaq MONDUX (Murcia)

Yuçaf MONDUX (Murcia)

Dauid ROCANCHO (Cieza)

Abrahim ROTYN (Murcia)

Mayr ROTYN (Murcia)

Cohen RUY (Murcia)

Rabi SAUCO (Murcia)

Abrahim TALAVI (Murcia)

Ysaaq TALAVI (Murcia)

Mosen TIMON (Murcia) 
GENOVESES RELACIONADOS CON EL CABILDO.

Gabriel CASTAÑO (1473)

Symon CASTAÑO (1469)

Batysta COMELIN (1472)

Tadeo de CASINELLO (1471)

DOMENICO (1471)

DOMERANQUE (1472)

Juan EMPERIAL (1474)

Juan Bautysta ESPINDOLA (1472)

Tadeo NIGRO (1471)

Juan ROTULO (1471)

Nycolaso SAULI (1473)

TERMO (1473) 